\title{
THE VALUE OF FORECASTING BYDV IN AUTUMN SOWN CEREALS
}

\author{
K. BICKNELL ${ }^{1}$, G. GREER ${ }^{1}$ and D.A.J. TEULON ${ }^{2}$ \\ ${ }^{1}$ Lincoln University, P.O. Box 84, Canterbury, New Zealand \\ ${ }^{2}$ Crop \& Food Research, Private Bag 4704, Christchurch
}

\begin{abstract}
Crop \& Food Research has developed a model to forecast the occurrence of severe barley yellow dwarf virus (BYDV) incidence in autumn-sown wheat crops in Canterbury based on alate aphid flights. This information is potentially valuable to growers in Canterbury, who can modify their inputs each year according to the risk of BYDV. This paper uses expected gross margins to estimate the financial benefit of the Crop \& Food Research BYDV Forecast Service to arable growers in Canterbury. Results suggest that the value of the BYDV Forecast Service is positive, but varies greatly depending upon forecast accuracy and adoption rate.
\end{abstract}

Keywords: BYDV, economic, forecast system, value of information.

\section{INTRODUCTION}

Since 1981Crop \& Food Research staff have carried out suction trapping for alate aphids in Canterbury during the autumn and winter. Using historical data collected at Lincoln between 1983 and 1991, Farrell and Stufkens (1992) estimated a significant relationship between aphid abundance during the autumn migration and the proportion of crops with infestations of BYDV greater than 5\%. This statistical relationship forms the basis of the Crop \& Food Research BYDV Forecast Service (Teulon et al. 1999).

Data on aphid flights is now collected from four sites throughout Canterbury and one site in Southland. Information on aphid flights and abundance is made available to growers through printed sources, a dedicated website (AphidWatch.com) and a telephone answer service. The objective of this paper is to estimate the financial benefit of the Crop \& Food BYDV Forecast Service to arable growers in Canterbury. The analysis presented below, using both survey data and data gathered from the literature, suggests that the value of the BYDV Forecast Service is certainly positive, but varies greatly depending upon the assumptions underlying the analysis.

\section{METHOD}

The benefits of the BYDV Forecast Service are derived from the extent to which growers can use the forecast information to improve their current control strategies. The standard method for estimating the value of information is to calculate the returns that a grower would expect to make without the information, and compare that to the returns that can be expected once the additional information has been incorporated into the decision making process (Pindyck and Rubinfeld 1996). The analysis presented below is based on a model developed by Watt (1983), modified to reflect current prices and strategies that are relevant to the control of BYDV in Canterbury. A more comprehensive description of the model can be found in Bicknell and Greer (1999).

\section{Value of a perfect forecast}

\section{RESULTS AND DISCUSSION}

The value of the Crop \& Food Research BYDV Forecast Service to an individual grower will depend on the control strategy they currently use and the way in which that control strategy is modified in response to additional information. A postal survey of arable farmers conducted for this research reveals that the most common method for 
controlling BYDV in Canterbury is to plant after mid-May to avoid the autumn aphid flight (see Bicknell and Greer (1999) for additional survey details), although more recently there has been a trend for earlier sowing. Research carried out by the Foundation for Arable Research indicates that late planting may involve a yield tradeoff for growers of some cultivars (Johnstone et al. 1998). The grower must decide, therefore, between slightly lower yields due to late planting, or the risk of substantially lower yields in years of severe BYDV outbreak.

For the purposes of this analysis, growers who plant early are assumed to choose one of three additional control strategies: i) to spray prophylactically, ii) to take no control measures at all or iii) to rely exclusively on the BYDV Forecast Service. These strategies can be represented in a pay-off matrix that displays the expected gross margins from each strategy (Table 1).

The gross margins in Table 1 are representative of a Canterbury wheat farmer using irrigation to achieve a medium yield of milling wheat. A detailed literature review, which provides background on the model assumptions, can be found in Bicknell and Greer (1999). Yield is assumed to be 6.5 tonnes/ha if planted before midMay. BYDV is assumed to suppress the yield of early-sown crops by $20 \%$ if no control measures are taken and by $5 \%$ if an aphicide has been applied. Late planting is associated with a yield loss of 5\%. Yield in late-sown crops is assumed to be suppressed by a further $5 \%$ in years of BYDV outbreak. Outbreak probabilities are 0.33 for late-sown crops and 0.42 for early sown crops. For ease of exposition the forecasting system is initially assumed to be $100 \%$ accurate. This restrictive assumption will be relaxed in subsequent analysis.

TABLE 1: Gross margin pay-off matrix for various control strategies (\$/ha of winter wheat at 1998 prices).

\begin{tabular}{lrcrr}
\hline & Sow Late & No Control & Prophylactic & Forecast \\
\hline No Outbreak & $\$ 779.75$ & $\$ 861.00$ & $\$ 827.16$ & $\$ 861.00$ \\
Outbreak & $\$ 702.56$ & $\$ 536.00$ & $\$ 745.91$ & $\$ 745.91$ \\
Expected Value & $\$ 754.28$ & $\$ 724.50$ & $\$ 793.04$ & $\$ 812.66$ \\
Standard Deviation & $\$ 36.29$ & $\$ 160.41$ & $\$ 40.10$ & $\$ 56.80$ \\
Value of the Forecast & $\$ 58.38$ & $\$ 88.16$ & $\$ 19.63$ & \\
\hline
\end{tabular}

The value of the perfect forecast can be calculated as the difference between two gross margins in Table 1. Given the assumptions outlined above, a grower using the forecast can expect to make nearly $\$ 20 /$ ha more, on average, than a grower using a prophylactic spraying regime, and $\$ 88 /$ ha more than a grower who does not control at all. Growers who plant early and use a completely accurate forecasting system can expect to make over $\$ 58 /$ ha more per hectare than those who delay planting to avoid the autumn aphid peak.

Unfortunately, the use of expected values masks the magnitude of the costs associated with making the 'wrong' decision in any given year. In years of severe BYDV outbreak, the cost of failing to control aphids is over $\$ 200 / \mathrm{ha}$. By contrast, the financial cost of spraying in a non-outbreak year is relatively low because aphicides can be tank-mixed with other chemicals and applied when controlling for other pests, weeds or diseases. At current prices the additional cost of an aphicide targeting BYDV vectors could be justified on economic grounds if it resulted in a yield increase of only $1.5 \%$.

The value of the perfect forecast is highly dependent upon the assumed values of the parameters. Fig. 1 demonstrates the relationship between expected gross margin and outbreak probability for the no control, prophylaxis and perfect forecast strategies. The no control strategy dominates the protective spray regime for very low probabilities of BYDV outbreak. For outbreak probabilities over $14 \%$, a prophylactic strategy results in a higher expected gross margin than the no control strategy. If the grower is 


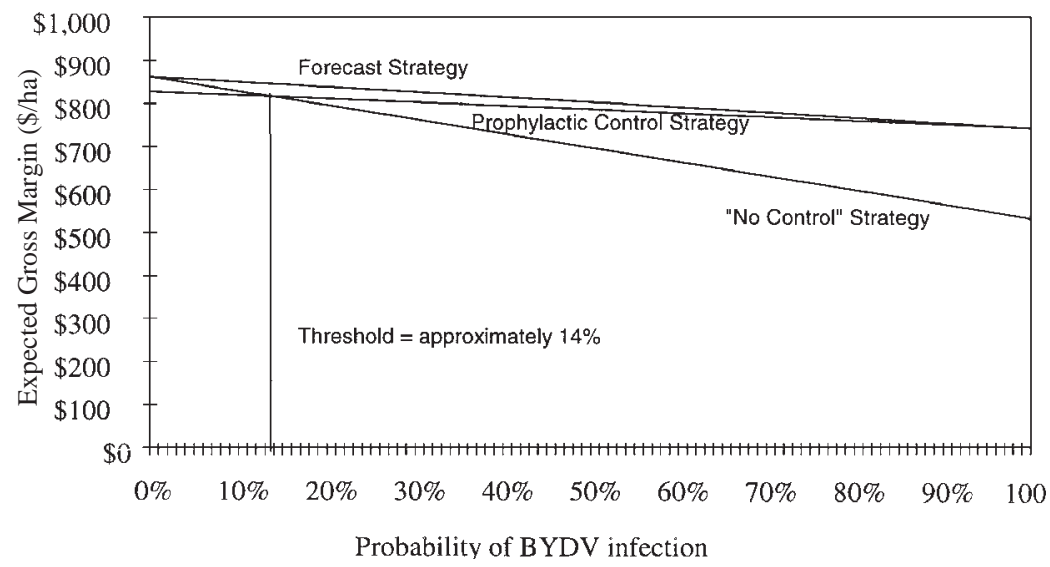

\section{FIGURE 1: Expected gross margin for winter wheat under various control} strategies.

assumed to choose the higher returning of the two alternative strategies, the value of the forecast can be represented as the vertical distance between the expected value of the forecast and the expected value of the next most profitable strategy for any outbreak probability. The value of the forecast for various outbreak probabilities is shown graphically in Fig. 2.

Forecast accuracy also has important implications for the optimal pest control strategy. Fig. 3 demonstrates that a strategy based solely on forecast information will not always result in the highest expected gross margin if the forecast is subject to error. If the forecast is $80 \%$ accurate, the forecast strategy is only optimal for outbreak probabilities between $3 \%$ and $39 \%$. For outbreak probabilities below 3\%, a no control strategy results in a higher expected gross margin. For outbreak probabilities above $39 \%$, a prophylactic spray regime is more profitable on average.

\section{Value of improving an existing monitoring system}

The majority of the growers in Canterbury who access the BYDV Forecast Service information use it to increase their awareness of the current risk of BYDV. The value of the forecast information for these growers is derived from the extent to which it will

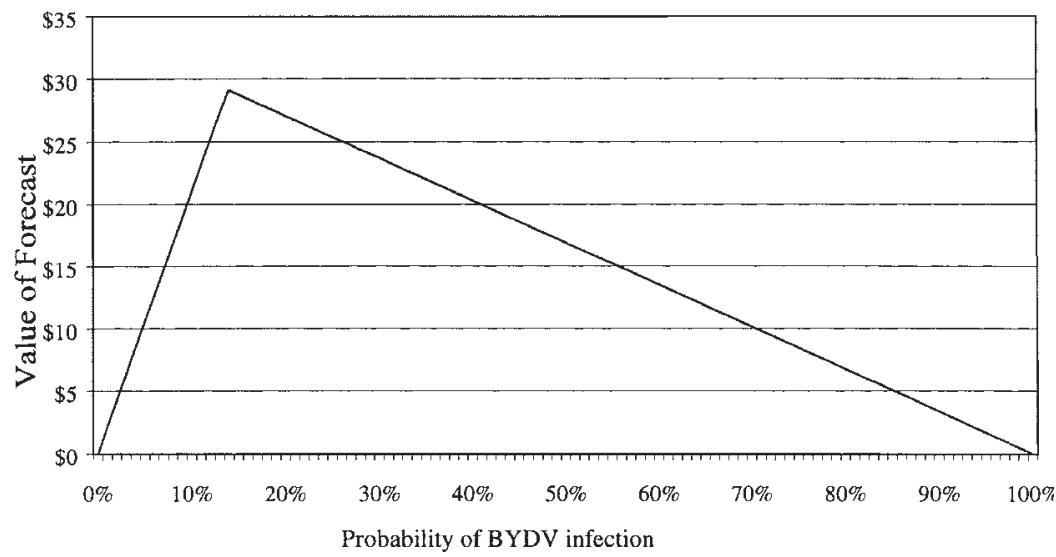

FIGURE 2: Value of a perfect forecast. 


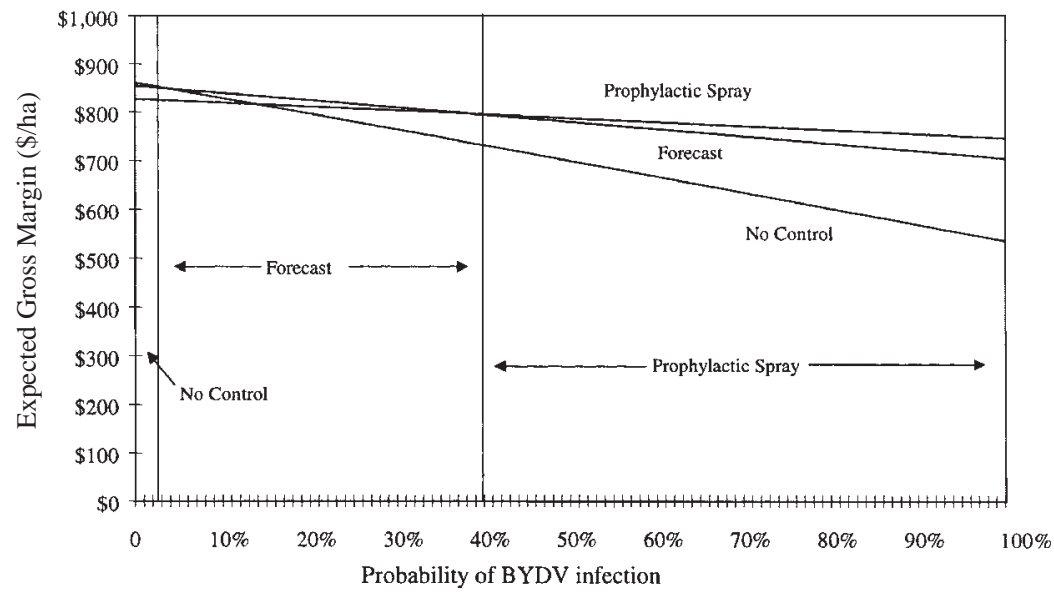

FIGURE 3: Expected gross margin for winter wheat with an imperfect forecast.

improve their own monitoring system. For illustrative purposes, suppose that a grower's existing monitoring system is accurate $50 \%$ of the time. The expected return from this 'self-monitoring' strategy is $\$ 759$ (Table 2). If, when using the BYDV Forecast Service information, the grower can improve the probability of spraying during a bad year to 0.9 and reduce the probability of spraying during a year when no outbreak occurs to 0.25 , their expected returns will increase to $\$ 799 /$ ha. The value of the BYDV Forecast Service to this grower is therefore approximately $\$ 40 / \mathrm{ha}$.

TABLE 2: Expected gross margin (\$/ha) for winter wheat as forecast accuracy improves.

\begin{tabular}{llccc}
\hline & \multicolumn{2}{c}{ Probabilities } & \multicolumn{2}{c}{ Values } \\
& Spray & Don't Spray & Spray & Don't Spray \\
\hline $\begin{array}{l}\text { Self Monitoring System } \\
\quad \text { No Outbreak }\end{array}$ & 0.5 & 0.5 & & \\
$\quad \begin{array}{l}\text { Outbreak } \\
\text { Expected Value }\end{array}$ & 0.5 & 0.5 & $\$ 827$ & $\$ 861$ \\
$\begin{array}{l}\text { Improved Monitoring System } \\
\quad \text { No Outbreak }\end{array}$ & & & $\$ 746$ & $\$ 536$ \\
$\quad \begin{array}{l}\text { Outbreak } \\
\text { Expected Value }\end{array}$ & 0.25 & 0.75 & & $\$ 759$ \\
$\quad 0.9$ & 0.1 & $\$ 827$ & $\$ 861$ \\
\hline
\end{tabular}

Fig. 4 shows the relationship between expected gross margin and outbreak probability for a forecast strategy that is $50 \%$ accurate, and for a strategy that fails to predict an outbreak $10 \%$ of the time and fails to predict a non-outbreak year $25 \%$ of the time. The vertical distance between the two lines in Fig. 4 represent the expected benefits of an improved monitoring system. When the probability of BYDV outbreak is $20 \%$, for example, the improved forecast increases the expected gross margin by approximately $\$ 22 / \mathrm{ha}$. The value of the forecast increases by approximately $\$ 0.83$ for each $1 \%$ increase in outbreak probability.

\section{Aggregate benefits of the BYDV Forecast Service}

The aggregate benefits of the BYDV Forecast Service information depend upon the accuracy of the forecast itself, and the extent to which growers throughout the region modify their behaviour in response to the information. Table 3 gives an 


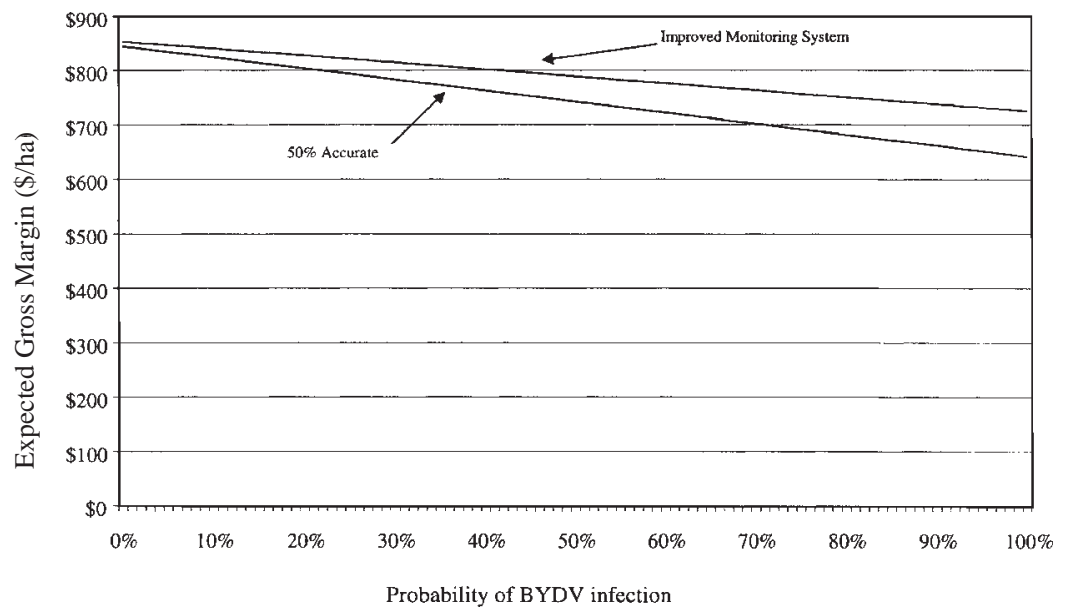

FIGURE 4: Expected gross margin for winter wheat as pest monitoring improves.

indication of the difference in gross margins for various control strategies, under a range of assumptions regarding the forecast accuracy.

A perfect forecast assumes that there will always be a BYDV outbreak when the BYDV Forecast Service indicates that alate aphid numbers are high, and that there will never be a BYDV outbreak when the Forecast Service indicates that aphid numbers are low. "Imperfect Forecast 1 " assumes that an outbreak is correctly predicted $90 \%$ of the time and a non-outbreak year is correctly predicted $75 \%$ of the time. "Imperfect Forecast 2" assumes that the BYDV Forecast Service is correct only $50 \%$ of the time. The self-monitoring strategy is evaluated under the conservative assumption that, in the absence of additional information, growers will only anticipate $50 \%$ of the outbreaks and $50 \%$ of the non-outbreak years. The expected gross margin associated with the self-monitoring system is therefore equal to the expected gross margin from the less accurate imperfect forecast scenario.

TABLE 3: Value of forecast as accuracy varies shown as the increase in expected gross margin for winter wheat.

Alternative control strategy

Forecast Accuracy

Perfect $\quad$ Imperfect $1 \quad$ Imperfect 2

\begin{tabular}{lccc}
\hline Late Planting & $\$ 58$ & $\$ 45$ & $\$ 4.50$ \\
Self-Monitor & $\$ 54$ & $\$ 40$ & $\$ 0$ \\
Protectant Spray & $\$ 20$ & $\$ 6$ & $(\$ 34)$ \\
No Control & $\$ 88$ & $\$ 75$ & $\$ 34$ \\
\hline
\end{tabular}

The aggregate benefits of the BYDV Forecast Service to Canterbury cereal growers under various assumptions regarding the level of adoption and forecast accuracy are presented in Table 4 . These figures were calculated by multiplying the increase in gross margin for each control strategy by an estimate of the amount of land subject to each control strategy. Area figures were extrapolated from survey results. In the case where an imperfect forecast results in a lower gross margin than prophylactic spraying, the grower was assumed to reject the forecast predictions and no benefit or cost was assumed.

Table 4 indicates that the annual expected benefits range from $\$ 29,000$ to over $\$ 1.3$ million, depending on forecast accuracy and level of adoption. Survey results 
indicate that the BYDV Forecast Service information is widely disseminated and that it does have an impact on the decision making process. While there is little empirical information available on the accuracy of the monitoring system, it is unlikely to be $100 \%$ reliable. Expected annual benefits are therefore most likely to be in the neighbourhood of $\$ 450,000$.

TABLE 4: Aggregate benefits from the BYDV Forecast Service in Canterbury.

\begin{tabular}{lrrr}
\hline & \multicolumn{3}{c}{ Adoption } \\
& $100 \%$ & $50 \%$ & $25 \%$ \\
\hline Perfect Forecast & $\$ 1,339,000$ & $\$ 669,000$ & $\$ 335,000$ \\
Imperfect Forecast 1 & $\$ 909,000$ & $\$ 454,000$ & $\$ 227,000$ \\
Imperfect Forecast 2 & $\$ 118,000$ & $\$ 59,000$ & $\$ 29,000$ \\
\hline
\end{tabular}

\section{REFERENCES}

Bicknell, K. and Greer, G., 1999. The value of the Crop \& Food Research BYDV forecast system to Canterbury arable farmers. Agribusiness and Economics Research Unit, Lincoln University, New Zealand.

Farrell, J. and Stufkens, M., 1992. Cereal aphid flights and barley yellow dwarf virus infection of cereals in Canterbury, New Zealand. N.Z. J. Crop Hort. Sci. 20: 407412.

Johnstone, J., Cameron, N. and Cookson, T., 1998. Early sowing of autumn wheat. FAR Arable Update No. 22, Foundation for Arable Research, Lincoln, New Zealand.

Pindyck, R. and Rubinfeld, D., 1995. Microeconomics. Prentice Hall, Englewood Cliffs, New Jersey.

Teulon, D.A.J., Stufkens, M.A.W., Nicol, D. and Harcourt, S.J., 1999. Forecasting barley yellow dwarf virus in autumn-sown cereals in 1998. Proc. 52nd N.Z. Plant Prot. Conf: : 187-191.

Watt, A., 1983. The influence of forecasting on cereal aphid control strategies. Crop Prot. 2(4): 417-429. 